\title{
New synonymy of Proceratium williamsi Tiwari (Hymenoptera, Formicidae)
}

\author{
Himender Bharti', Aijaz Ahmad Wachkoo' \\ I Department of Zoology \& Environmental Sciences, Punjabi University, Patiala - 147002, India \\ Corresponding author: Himender Bharti (himenderbharti@gmail.com)
}

Academic editor: B. Fisher | Received 7 January 2014 | Accepted 5 February 2014 | Published 13 March 2014

Citation: Bharti H, Wachkoo AA (2014) New synonymy of Proceratium williamsi Tiwari (Hymenoptera, Formicidae). ZooKeys 388: 69-72. doi: 10.3897/zookeys.388.6972

\begin{abstract}
Proceratium bhutanense De Andrade, 2003, syn. n. is here found to be conspecific with Proceratium williamsi Tiwari, 2000 and accordingly treated as a junior synonym.
\end{abstract}

\section{Keywords}

Ants, Proceratium bhutanense, Proceratium williamsi, synonymy, India

\section{Introduction}

At present 79 extant and 5 fossil species are listed in the ant genus Proceratium across the globe (Bolton et al. 2007; Bolton 2012). In India, this genus is represented by two species (Bharti 2011). Proceratium williamsi was described by Tiwari (2000) as the first record of the genus from India; shortly afterwards De Andrade (2003) added $P$. bhutanense to the Indian Proceratium.

Unfortunately, Baroni Urbani and De Andrade (2003) left out $P$. williamsi from their global taxonomic revision of Proceratium, possibly due to lack of access to an obscure paper published locally. However, re-examination of both Indian species finds them conspecific. The specimens of $P$. williamsi collected by R. Mathew from the type 
locality Meghalaya, Khasi hills, Shillong also form part of the material examined for $P$. bhutanense. Descriptions, morphometrics, line drawings, images and collection localities of two are also akin. Therefore, $P$. bhutanense is considered here as a junior synonym of $P$. williamsi.

\section{Material and methods}

The morphological observation was conducted on a Nikon SMZ 1500 stereo zoom microscope. For digital images, MP evolution digital camera was used on the same microscope with Auto-Montage (Syncroscopy, Division of Synoptics, Ltd.) software. Later, images were cleaned as required with Adobe Photoshop CS5.

Abbreviations of the specimen depositories are:

BMNH The Natural History Museum, London, England, U.K.

MRSN Museo Regionale di Scienze Naturali, Torino, Italy.

NHMB Naturhistorisches Museum Basel, Switzerland.

PUPAC Punjabi University Patiala, Ant Collection, Patiala, India.

ZSIK Zoological Survey of India, Kolkata, India.

\section{Results and discussion}

\section{Proceratium williamsi Tiwari, 2000}

http://species-id.net/wiki/Proceratium_williamsi

Figs $1-3$

Proceratium williamsi Tiwari, in Mathew and Tiwari 2000: 272, Figs 14-15 (w.). Holotype and paratype workers: Meghalaya, Khasi hills, Shillong, India [ZSIK].

Proceratium bhutanense De Andrade, in Baroni Urbani and De Andrade 2003: 278, Figs 116-117 (w.). Holoype and paratype workers: Phuntsholing, Bhutan [NHMB]; one paratype worker Phuntsholing, Bhutan [MRSN]. Syn. n.

Material examined. Paratype, worker, Meghalaya, Khasi hills, Shillong, India [ZSIK]; Worker [BMNH] (coll. R. Mathew, Det. De Andrade); worker photographs also examined on AntWeb (www.antweb.org): CASENT0281860. Other Material: Uttarakhand: Dakpathar, 750m, 4 (w.), 20.viii.2009; Rajaji Forest Area, 660m, 3(w.), 11.viii.2009, 1(w.), 12.viii.2009 (coll. Aijaz A. Wachkoo) [PUPAC]. West Bengal: Darjeeling, 1850m, 4(w.), 20.vi.2009 (coll. Irfan Gul) [PUPAC]. Meghalaya: Cherapunji, 1200m, 3(w.), 2.iv.2009 (coll. Irfan Gul); Khasi hills, Shillong, 1496m, 3(w.), 1(q.), 10.iv.2009 (coll. Irfan Gul) [PUPAC].

Ecology. This species was found mainly in leaf litter of primary, subtropical forests of Himalaya and occasionally in soil samples of secondary forests collected in cool 

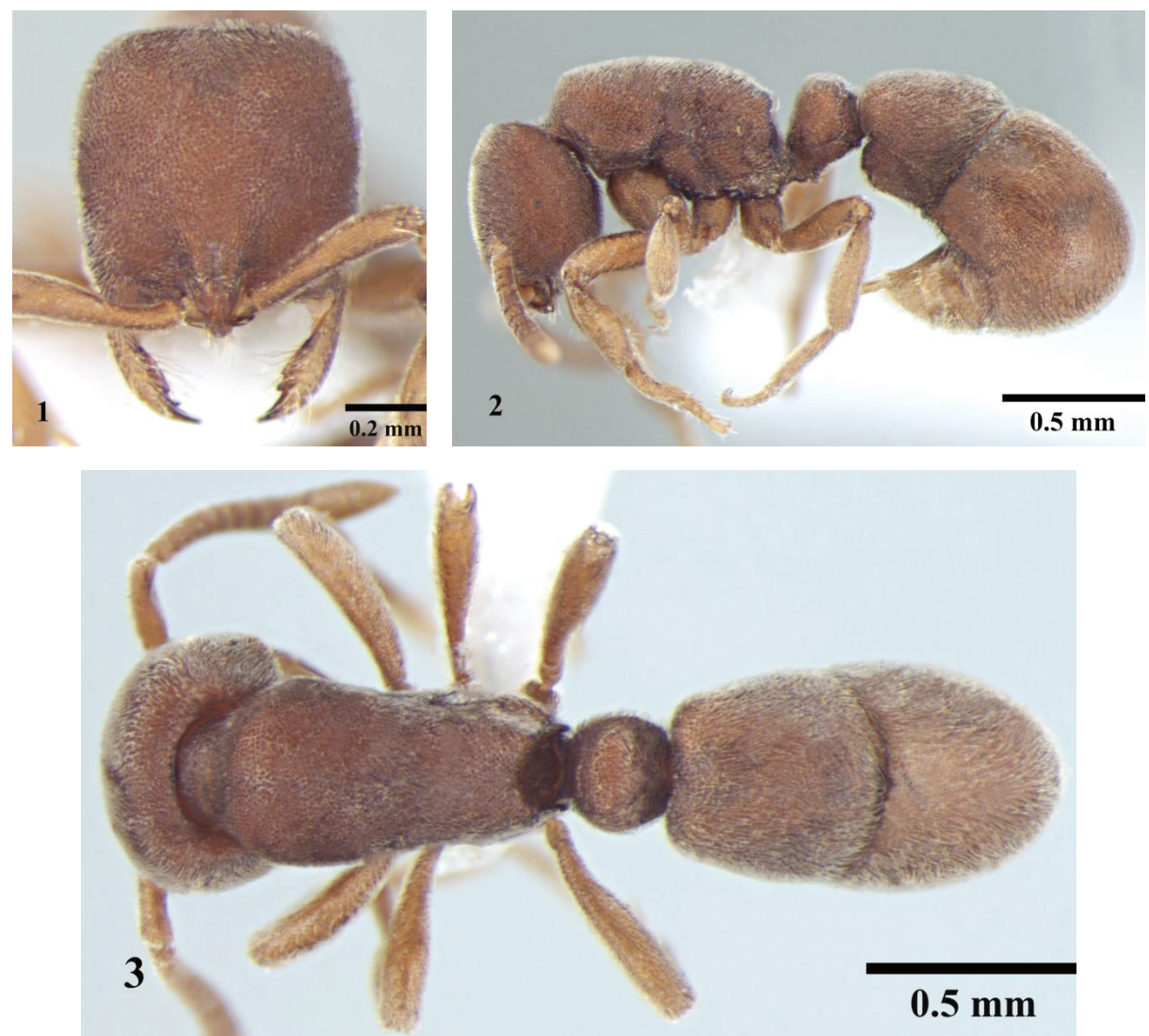

Figures I-3. Worker; Proceratium williamsi Tiwari, 2000. I Head in full-face view 2 Body, lateral view 3 Body, dorsal view.

shady places. Although infrequent in collections, this species seems to be widely distributed throughout the Himalayan ranges.

Remarks. Examination of the specimens coupled with the images and descriptions reveal that there are no characters which could delimit P. bhutanense and P. williamsi. Moreover, the studied material does not exhibit any marked variation throughout the collection range, thereby enabling us to confidently treat $P$. bhutanense as a junior synonym of $P$. williamsi.

\section{Acknowledgments}

Financial assistance rendered by the Ministry of Environment and Forests (grant no. 14/10/2007 ERS/RE), Govt. of India, New Delhi is gratefully acknowledged. Sincere thanks to Ms. Suzanne Ryder (BMNH) for her cooperation during the visit of the senior author to the Natural History Museum. 


\section{References}

Baroni Urbani C, De Andrade ML (2003) The ant genus Proceratium in the extant and fossil record. Museo Regionale di Scienze Naturali - Torino Monographie 36: 1-492.

Bharti H (2011) List of Indian Ants (Hymenoptera: Formicidae). Halteres 3: 79-87.

Bolton B (2012) An Online Catalog of the Ants of the World. AntCat. http://www.antcat.org/ Bolton B, Alpert G, Ward PS, Naskrecki P (2007) Bolton's Catalogue of Ants of the World: 1758-2005 [CD-ROM]. Harvard University Press, Cambridge, Massachusetts.

Mathew R, Tiwari RN (2000) Insecta: Hymenoptera: Formicidae, Fauna of Meghalaya, Part 7 State Fauna Series 4. Zoological Survey of India, Calcutta, 409 pp. 